\title{
The Effect of Vanadium and Niobium on the Properties and Microstructure of the Intercritically Reheated Coarse Grained Heat Affected Zone in Low Carbon Microalloyed Steels
}

\author{
Y. LI, D. N. CROWTHER, ${ }^{1)}$ M. J. W. GREEN, ${ }^{1)}$ P. S. MITCHELL ${ }^{2)}$ and T. N. BAKER \\ Metallurgy and Engineering Materials Group, Department of Mechanical Engineering, University of Strathclyde, Glasgow, G1 \\ 1XJ, UK. $\quad$ 1) Corus Group, Swinden Technology Centre, Moorgate, Rotherham, S60 3AR, UK. \\ 2) Vanitec, Winterton House, High Street, Westerham, Kent, TN16 1AJ, UK.
}

(Received on July 25, 2000; accepted in final form on September 19, 2000)

\begin{abstract}
Four steels, C-Mn-0.05V, C-Mn-0.11V, C-Mn and C-Mn-0.03Nb, all essentially boron-free were subjected to processing to simulate the microstructure of a coarse grained heat affected zone (GC HAZ) and an intercritically reheated coarse grained HAZ (IC GC HAZ). This involved reheating to $1350^{\circ} \mathrm{C}$, rapid cooling $\left(\Delta t_{8 / 5}=24 \mathrm{~s}\right)$ to room temperature and then reheating to either $750^{\circ} \mathrm{C}$ or $800^{\circ} \mathrm{C}$. The toughness of the simulated GC HAZ and IC GC HAZ was assessed using both Charpy and CTOD tests and the hardness of both zones was also measured. A detailed assessment of the size and area fraction of martensite-austenite (MA) phase in the IC GC HAZ in the steels was obtained from a combination of Scanning Electron Microscopy (SEM) and Image Analysis of the resultant SEM micrographs. In addition, the distribution of the M-A phase was examined by observing 250 fields at a magnification of 2500 times in the SEM for each of the steels.

It is clear that the alloying addition has a significant effect on the amount and size of the M-A phase. The addition of $0.05 \% \mathrm{~V}$ to the C-Mn steel resulted in the lowest IC GC HAZ Charpy 50J impact transition temperature and the $0.1 \mathrm{~mm}$ CTOD transition temperature. The corresponding size and area fraction of the M-A phase were the smallest of the four steels. Raising the level of vanadium to $0.11 \%$ caused a deterioration in IC GC HAZ toughness, which was reflected in a greater area fraction of M-A phase, larger mean and maximum sizes of M-A particles and significantly more fields containing M-A phase. The addition of $0.03 \% \mathrm{Nb}$ produced poorer IC GC HAZ toughness data than $\mathrm{C}-\mathrm{Mn}-\mathrm{V}$ and $\mathrm{C}-\mathrm{Mn}$ steels and this was related to the large size and area fraction of M-A phase quantified in the Nb steel. The presence of M-A phase is considered to be the dominant factor in determining the toughness of IC GC HAZ.
\end{abstract}

KEY WORDS: V-microalloyed steel; Nb-microalloyed steel; coarse grained heat affected zone; intercritically reheated coarse grained heat affected zone; martensite-austenite phase; heat affected zone toughness; welding.

\section{Introduction}

The balance of high strength and good toughness in HSLA steels can be upset by the thermal cycles experienced during welding, producing poor toughness in the heat affected zone (HAZ). Historically, the lowest toughness was expected in the grain coarsened heat affected zone (GC HAZ), which is the part of the HAZ immediately adjacent to the weld fusion line. ${ }^{1)}$ During welding, the GC HAZ experiences peak temperatures up to the melting point, followed by rapid cooling. The high temperatures can lead to significant austenite grain coarsening, and the combination of a coarse austenite grain size and rapid cooling promotes brittle microstructures, which contain high proportions of ferrite side-plates and bainite. In recent years, it has been found that the most degraded part in the HAZ is the intercritically reheated coarse grained HAZ (IC GC HAZ), which is the region of the GC HAZ heated to temperatures between the $\mathrm{Ac}_{1}$ and $\mathrm{Ac}_{3}$ by subsequent welding passes. ${ }^{2,3)}$ During the intercritical thermal cycle, partial transformation to austenite occurs, particularly where austenite stabilisers, such as carbon or manganese, are segregated in the initial microstructure. These areas include pearlite/bainite colonies. ${ }^{4)}$ On cooling, these high carbon regions transform to pearlite/bainite or martensite-austenite (M-A) constituents, depending on the hardenbility of the austenite and cooling rate. The presence of M-A phase is generally regarded as the major factor which reduces the HAZ toughness. ${ }^{5,6)}$ However, it is also reported that the loss in toughness is not solely due to the presence of M-A phase, but is related to the distribution and morphology of the M-A constituent, and the matrix microstructure. ${ }^{7}$

Niobium is added to enhance the strength of HSLA steels. However, under welding conditions, niobium has an 
effect on the HAZ toughness, although its effect is strongly dependent on heat input. At medium to high heat input, and quite apart from a precipitation hardening effect via $\mathrm{Nb}(\mathrm{C}$, $\mathrm{N}$ ), niobium has a detrimental influence on the fracture toughness of coarse grained HAZs. ${ }^{8,9)}$ Niobium reduces the grain boundary ferrite and promotes formation of a coarse structure of ferrite with aligned M-A-C (martensite-austenite-carbide) resulting in increased hardness. A small addition of niobium $(\sim 0.02 \%)$ is known to suppress ferrite nucleation at prior austenite grain boundaries and increase the volume fraction of martensite or bainite. ${ }^{10,11)}$ Lee et al.$^{6)}$ reported that the major advantages of a niobium addition, i.e. the grain refinement and the resultant improvement of base metal mechanical properties, appear to be outweighed by the detrimental effects of martensite formation, when the steel plates are welded.

Vanadium gives grain refinement and precipitation strengthening to HSLA steels. The effect of vanadium on the GC HAZ microstructure is quite different from that of niobium. Vanadium has a beneficial effect on the toughness of the GC HAZ, because it reduces the bainitic colony size and promotes intragranular nucleation of acicular ferrite. ${ }^{8,12,13)}$ However, the role of vanadium on the toughness of the IC GC HAZ and on the formation of M-A phase within the IC GC HAZ is not fully understood. It has been reported $^{14,15)}$ that vanadium has a detrimental effect on the toughness of the IC GC HAZ, because vanadium can promote the formation of the potentially brittle M-A phase. However, other research ${ }^{16-18)}$ showed that the addition of low level of vanadium (about $0.05 \% \mathrm{~V}$ ) to the low carbon steels reduced the size and area fraction of M-A phase and improved IC GC HAZ toughness.

The objective of this study was to assess the influence of vanadium and niobium on the properties and microstructure of the simulated IC GC HAZ in nominally $0.1 \% \mathrm{C}$ and $1.4 \%$ Mn steels.

\section{Experimental Procedure}

The steels were made by vacuum melting, cast to give $50 \mathrm{~kg}$ ingots, and subsequently control-rolled to $30 \mathrm{~mm}$ thick plates. The compositions of the steels are given in Table 1. These are essentially $0.1 \% \mathrm{C}, 1.4 \% \mathrm{Mn}, 0.2 \% \mathrm{Si}$, $0.03 \% \mathrm{Al}$ and $0.005 \% \mathrm{~N}$ steels with levels of boron $<$ $0.0005 \%$. Two of the steels, Steel LV and Steel V were microalloyed with vanadium additions of $0.05 \%$ and $0.11 \%$ respectively. For comparison purposes, two other steels were also included in the study. They were an $0.03 \% \mathrm{Nb}$ steel (Steel $\mathrm{Nb}$ ) and a $\mathrm{C}-\mathrm{Mn}$ steel (Steel C). The as-rolled plate contained fine-grained ferrite with a clear-banded distribution of pearlite. The microstructural data and mechanical properties of the base plates are given in Table 2.

Since the size of the IC GC HAZ is very small, a study of this region is particularly difficult in a real weld. Therefore, a thermal simulation was used to generate a relatively large region of IC GC HAZ, which allowed the notch to be reliably located in the correct microstructure. The steels were subjected to a double-pass welding thermal simulation. Thermal simulation test blanks were cut from the sub-surface position of each plate, with the test piece axis transverse to the rolling direction. Test blanks, $11 \times 11 \mathrm{~mm}$
Table 1. Chemical composition of the steels. (wt \%)

\begin{tabular}{|c|c|c|c|c|c|}
\hline Code & $\mathbf{C}$ & $\mathbf{S i}$ & $\mathbf{M n}$ & $\mathbf{P}$ & $\mathbf{S}$ \\
\hline Steel C & 0.092 & 0.20 & 1.41 & 0.005 & 0.004 \\
\hline Steel LV & 0.084 & 0.21 & 1.42 & 0.005 & 0.002 \\
\hline Steel V & 0.094 & 0.21 & 1.44 & 0.005 & 0.003 \\
\hline Steel Nb & 0.100 & 0.19 & 1.40 & 0.005 & 0.002 \\
\hline Code & $\mathbf{A l}$ & $\mathbf{N}$ & $\mathbf{N b}$ & $\mathbf{V}$ & $\mathbf{B}$ \\
\hline Steel C & 0.039 & 0.0067 & $<0.005$ & $<0.005$ & $<0.0005$ \\
\hline Steel LV & 0.031 & 0.0047 & $<0.005$ & 0.05 & $<0.0005$ \\
\hline Steel V & 0.029 & 0.0052 & $<0.005$ & 0.10 & $<0.0005$ \\
\hline Steel Nb & 0.031 & 0.0040 & 0.031 & $<0.005$ & $<0.0005$ \\
\hline
\end{tabular}

Table 2. Microstructural data and mechanical properties of the parent plates.

\begin{tabular}{|c|c|c|c|c|c|c|c|}
\hline Code & $\begin{array}{c}\text { UYS } \\
(\mathbf{M P a})\end{array}$ & $\begin{array}{c}\text { LYS } \\
(\mathbf{M P a})\end{array}$ & $\begin{array}{c}\text { UTS } \\
(\mathbf{M P a})\end{array}$ & $\begin{array}{c}\text { \%EL } \\
(\mathbf{\%})\end{array}$ & $\begin{array}{c}\text { 27J ITT } \\
\left({ }^{\circ} \mathbf{C}\right)\end{array}$ & $\begin{array}{c}\text { Grain size } \\
(\mu \mathbf{m})\end{array}$ & $\begin{array}{c}\text { Pearlite } \\
(\%)\end{array}$ \\
\hline Steel C & 357 & 291 & 448 & 37 & -75 & 11.3 & 14 \\
\hline Steel LV & 335 & 322 & 450 & 40 & -85 & 13.5 & 13 \\
\hline Steel V & 416 & 363 & 493 & 34 & -75 & 7.8 & 13 \\
\hline Steel Nb & 383 & 358 & 484 & 36 & -70 & 10.5 & 14 \\
\hline
\end{tabular}

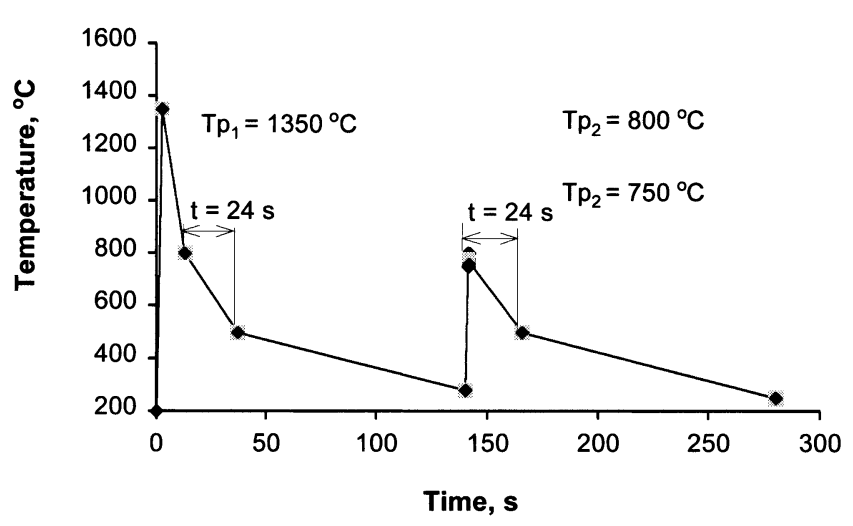

Fig. 1. Simulated weld thermal cycles.

in size, were used, and following thermal simulation, the blanks were machined to a $10 \times 10 \mathrm{~mm}$ size for Charpy or CTOD test pieces. The weld HAZ thermal simulations were performed on a Gleeble 1500 simulator. The thermal cycles used in the simulated double-pass welding in this study are show in Fig. 1. The GC HAZ thermal cycle was designed to simulate a submerged arc weld of approximately $3.6 \mathrm{~kJ} /$ $\mathrm{mm}$ heat input in $25 \mathrm{~mm}$ thick plate. This involved heating to a peak temperature $\left(\mathrm{Tp}_{1}\right)$ of $1350^{\circ} \mathrm{C}$ at a rate of approximately $480^{\circ} \mathrm{C} / \mathrm{s}$ and holding at the peak temperature for $0.35 \mathrm{~s}$, followed by cooling between $800^{\circ} \mathrm{C}$ and $500^{\circ} \mathrm{C}$ $\left(\Delta t_{8 / 5}\right)$ in $24 \mathrm{~s}$. The intercritical cycles were conducted at peak temperatures $\left(\mathrm{Tp}_{2}\right)$ of 750 and $800^{\circ} \mathrm{C}$ respectively, and the heating rates, the times at peak temperature and the cooling rates $\left(\Delta t_{8 / 5}\right)$, were the same as in the GC HAZ thermal cycle. The peak temperatures were chosen to be similar to those in the reports in the literature, which showed a reduced toughness due to $\mathrm{M}-\mathrm{A}$ formation in this temperature interval. ${ }^{14,19)}$ There was some variation in the peak temperature attained in both the grain coarsening and intercritical cycles, and samples were only accepted if the deviations from the aimed peak temperatures were within $\pm 10^{\circ} \mathrm{C}$.

Metallographic specimens were taken from both the weld simulated GC HAZ and IC GC HAZ. The specimens were metallographically prepared by standard techniques and the microstructures of the simulated HAZs were examined by optical microscopy and scanning electron microscope (SEM). A quantitative metallographic examination was also completed in the simulated specimens to study the influence of vanadium and niobium on the simulated IC GC 
HAZ microstructure. Prior austenite grain size in the GC HAZ was measured by a linear intercept method and a minimum 200 grains were counted for each specimen. The size and the area fraction of the M-A phase in the IC GC HAZ were measured by means of an image analyser, from SEM micrographs at a magnification of 5000 times. At least 300 particles were measured for each of the steels. The distributions and morphology of the M-A phase in prior austenite grains or on the prior austenite grain boundaries were analysed by observing 250 fields on the SEM display screen for each specimen, at a magnification of 2500 times. The screen size is $23 \times 17 \mathrm{~cm}$.

The $10 \times 10 \mathrm{~mm}$ thermally simulated test blanks were etched to reveal the position of the HAZ. $10 \times 10 \mathrm{~mm}$ Charpy test pieces were notched with a ' $V$ ' notch of $2 \mathrm{~mm}$ depth and the notch tip placed in the centre of the HAZ. Charpy impact tests were performed in accordance with BS EN 10045 to produce a complete transition curve. The test temperatures were in the range of $-80^{\circ} \mathrm{C}$ to $60^{\circ} \mathrm{C}$. $10 \times$ $10 \mathrm{~mm}$ CTOD test pieces were also produced from the thermal simulated test blanks with a $3 \mathrm{~mm}$ deep through-thickness notch cut into the sample. The position of the notch was again in the centre of the etched HAZ. The notch orientation was such that the crack propagation direction was parallel to the plate rolling direction. A fatigue crack of $2 \mathrm{~mm}$ nominal depth was then grown into the specimen, giving a nominal a/W (overall crack depth/specimen width) value of 0.5 . The CTOD samples were then tested, following BS $7448: 1991$, to produce a complete ductile-brittle transition curve. A test temperature range of $-160^{\circ} \mathrm{C}$ to $60^{\circ} \mathrm{C}$ was used. Vickers hardness tests were also performed on the simulated HAZ specimens, to BS 427 , using a $30 \mathrm{~kg}$ load.

Fractographic examinations of the Charpy and CTOD specimens were undertaken to allow a better understanding of the micromechanisms of fracture under different microstructural and test conditions. The broken Charpy impact specimens and CTOD specimens were ultrasonically cleaned in an acetone bath and then dried prior to SEM examination. Some fracture surfaces were given a long (2$3 \mathrm{~min}$ ) 2\% nital etch before examination, to reveal the microstructural features on the cleavage facets. Vertical sections of fractured Charpy or CTOD specimens were also examined to clarify if cleavage fracture was related to M-A constituents particles. Fractured halves were first nickelplated to avoid rounding during polishing and then sectioned longitudinally.

\section{Results}

\subsection{Mechanical Property and Toughness in the Simulated HAZ}

The mechanical properties of the simulated HAZ in the steels are given in Table 3 while the effects of vanadium and niobium on the hardness in the GC HAZ and IC GC HAZ are shown in Fig. 2. The Vickers hardness of the GC HAZ was similar in the vanadium and niobium steels (about 202-208 HV). Compared with the other steels, Steel $\mathrm{C}$ had the lowest Vickers hardness value (187 HV). Following the intercritical reheating, the hardness in Steel $\mathrm{V}$ and Steel $\mathrm{Nb}$ were virtually unchanged, but decreased in
Table 3. Mechanical property and toughness of the simulated HAZs.

\begin{tabular}{|c|c|c|c|}
\hline \multirow{2}{*}{ Properties $\quad \mathrm{HAZ}$} & \multicolumn{3}{|c|}{ Steel C } \\
\hline & GC HAZ & IC GC HAZ $750^{\circ} \mathrm{C}$ & $\begin{array}{c}\text { IC GC HAZ } \\
800^{\circ} \mathrm{C}\end{array}$ \\
\hline Hardness (HV30) & 187 & 171 & 169 \\
\hline 50J ITT $\left({ }^{\circ} \mathrm{C}\right)$ & -55 & -10 & -25 \\
\hline $0.1 \mathrm{~mm}$ CTOD TT $\left({ }^{\circ} \mathrm{C}\right)$ & -105 & -35 & -75 \\
\hline \multirow{2}{*}{ Properties $\quad$ HAZ } & \multicolumn{3}{|c|}{ Steel LV } \\
\hline & GC HAZ & IC GC HAZ $750^{\circ} \mathrm{C}$ & $\begin{array}{c}\text { IC GC HAZ } \\
800^{\circ} \mathrm{C}\end{array}$ \\
\hline Hardness (HV30) & 202 & 192 & 187 \\
\hline $50 \mathrm{~J} \mathrm{ITT}\left({ }^{\circ} \mathrm{C}\right)$ & -70 & -35 & -35 \\
\hline $0.1 \mathrm{~mm}$ CTOD TT $\left({ }^{\circ} \mathrm{C}\right)$ & -130 & -60 & -80 \\
\hline \multirow{2}{*}{ Properties $\quad$ HAZ } & \multicolumn{3}{|c|}{ Steel V } \\
\hline & GC HAZ & IC GC HAZ $750^{\circ} \mathrm{C}$ & $\begin{array}{c}\text { IC GC HAZ } \\
800^{\circ} \mathrm{C}\end{array}$ \\
\hline Hardness (HV30) & 208 & 207 & 204 \\
\hline 50J ITT $\left({ }^{\circ} \mathrm{C}\right)$ & -50 & -10 & 0 \\
\hline $0.1 \mathrm{~mm}$ CTOD TT $\left({ }^{\circ} \mathrm{C}\right)$ & -110 & -25 & -10 \\
\hline \multirow{2}{*}{$\begin{array}{ll}\text { Properties } & \text { HAZ } \\
\end{array}$} & \multicolumn{3}{|c|}{ Steel Nb } \\
\hline & GC HAZ & IC GC HAZ $750^{\circ} \mathrm{C}$ & $\begin{array}{c}\text { IC GC HAZ } \\
800^{\circ} \mathrm{C}\end{array}$ \\
\hline Hardness (HV30) & 203 & 208 & 206 \\
\hline 50J ITT $\left({ }^{\circ} \mathrm{C}\right)$ & -60 & -10 & 10 \\
\hline $0.1 \mathrm{~mm}$ CTOD TT $\left({ }^{\circ} \mathrm{C}\right)$ & -85 & -15 & -25 \\
\hline
\end{tabular}

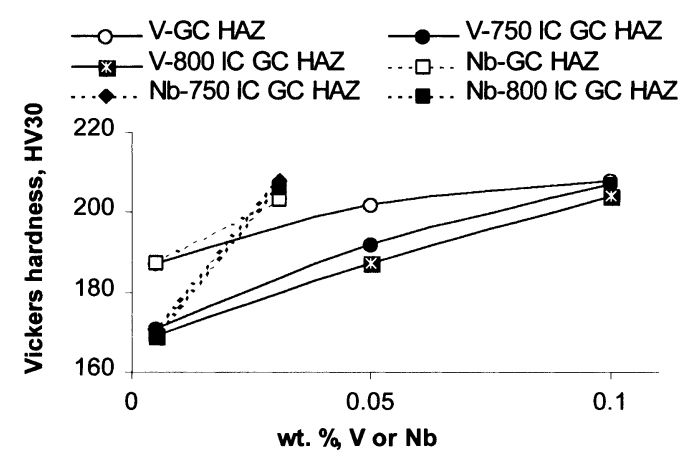

Fig. 2. The effects of vanadium and niobium on the hardness in the GC HAZ and IC GC HAZ.

Steel LV and Steel C. Again, the hardness in Steel C was lower than the other steels. There was little variation in the hardness values with respect to the intercritical reheating temperature.

Charpy impact and $0.1 \mathrm{~mm}$ CTOD results of the steels for different conditions are also summarised in Table 3 . The effects of vanadium and niobium on the 50J ITT and $0.1 \mathrm{~mm}$ CTOD TT are displayed in Figs. 3 and 4. The GC HAZ Charpy impact transition temperatures were similar for the steels, except that Steel LV had a slightly lower 50J ITT of $-70^{\circ} \mathrm{C}$ compared with the others. The Charpy impact toughness of the steels deteriorated in the simulated IC GC HAZ. The Nb steel exhibited a greater degradation of impact toughness after $800^{\circ} \mathrm{C}$ intercritical cycle, with a $50 \mathrm{~J}$ ITT of $+10^{\circ} \mathrm{C}$. Steel LV had a superior impact toughness to the other steels in both the GC HAZ and IC GC HAZ conditions. The impact toughness decreased as the vanadium content increased to $0.11 \%$ in all cases.

All the steels showed good fracture toughness in the GC HAZ condition, with $0.1 \mathrm{~mm}$ CTOD transition temperatures between $-85^{\circ} \mathrm{C}($ Steel $\mathrm{Nb})$ and $-130^{\circ} \mathrm{C}$ (Steel LV). Steel C and Steel $\mathrm{V}$ had similar $0.1 \mathrm{~mm}$ CTOD transition temperatures of $-105^{\circ} \mathrm{C}$ and $-110^{\circ} \mathrm{C}$ respectively. The steels exhibited significantly poorer fracture toughness after the intercritical cycles, which indicated that the IC GC HAZ is the local brittle zone in the HAZs. After the $750^{\circ} \mathrm{C}$ intercritical reheating, Steel LV had the lowest $0.1 \mathrm{~mm}$ CTOD transition temperature of $-60^{\circ} \mathrm{C}$. Again, Steel $\mathrm{Nb}$ had the 


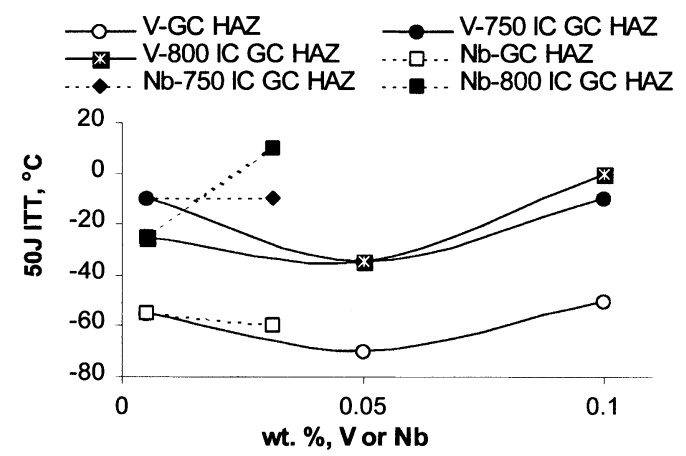

Fig. 3. The effects of vanadium and niobium on the 50J ITT of the GC HAZ and IC GC HAZ.

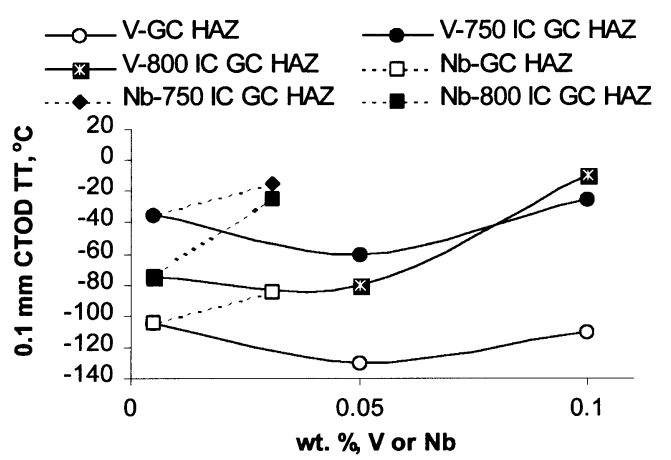

Fig. 4. The effects of vanadium and niobium on the $0.1 \mathrm{~mm}$ CTOD TT.
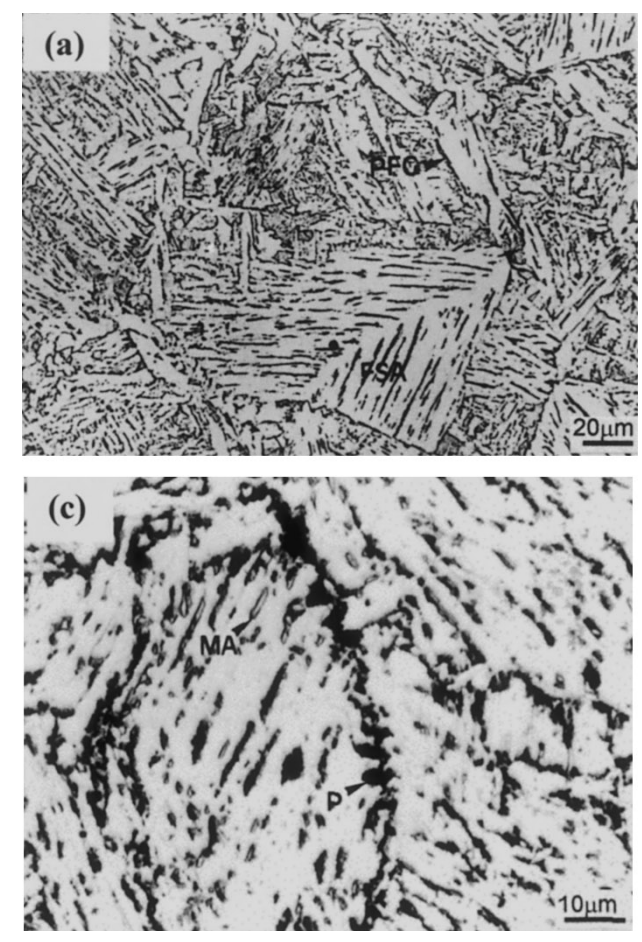
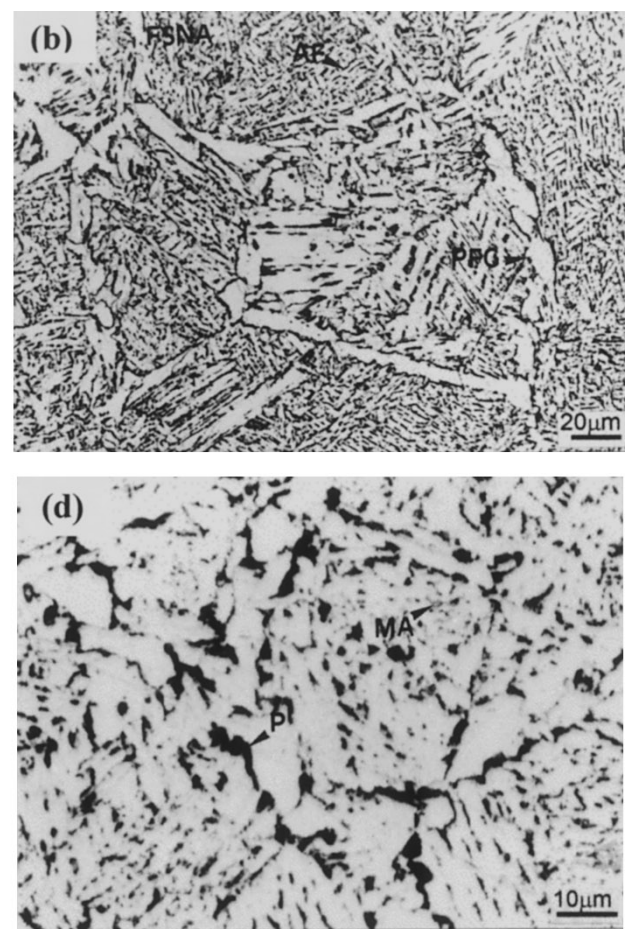

Fig. 5.

Optical micrographs showing the microstructure in the GC HAZ (a) for Steel C and (b) Steel LV, and in the IC GC HAZ for (C) Steel C and (d) Steel LV. FS(A) - ferrite side-plate; PFG primary ferrite on the prior austenite grain boundary; FS(NA) - ferrite with non-aligned second phase; AF - acicular ferrite; $\mathrm{P}$ - pearlite; MA - martensite-austenite. highest $0.1 \mathrm{~mm}$ CTOD transition temperature, $-15^{\circ} \mathrm{C}$. For the $800^{\circ} \mathrm{C}$ intercritical cycle, the $0.1 \mathrm{~mm}$ CTOD transition temperatures of Steel $\mathrm{C}$ and Steel $\mathrm{LV}$ were similar, $-75^{\circ} \mathrm{C}$ and $-80^{\circ} \mathrm{C}$ respectively, which were much lower than those of Steel $\mathrm{Nb}\left(-25^{\circ} \mathrm{C}\right)$ and Steel V $\left(-10^{\circ} \mathrm{C}\right)$. Again Steel LV showed a superior fracture toughness to the other steels in all the conditions examined.

\subsection{Microstructure of the Simulated HAZ}

The prior austenite grain size in the GC HAZ was similar in the steels. The majority of results were within the range $120-150 \mu \mathrm{m}$. However, differences in the matrix microstructures of the simulated HAZ of the steels were observed. In the GC HAZ condition, the grain boundary ferrite consisted of numerous polygonal ferrite grains in the vanadium steels, compared with films of grain boundary ferrite in the carbon manganese steel. The intragranular structure of the vanadium steels was much finer, with increased proportions of acicular ferrite, a reduced bainite colony size and very few coarse ferrite side-plates, which were a common feature in the carbon manganese steel. The niobium steel contained a much lower grain boundary ferrite content compared with the other steels, and tended to have an increased proportion of ferrite side-plates. After intercritical reheating, the differences in the matrix microstructures in the GC HAZ of the steels tended to be maintained in the IC GC HAZ. Examples of the microstructure in the GC HAZ and IC GC HAZ for Steel C and Steel LV are shown in Fig. 5.

The microstructures in the IC GC HAZ were also examined using SEM. Examples showing the M-A phase in a number of forms are given in Fig. 6 The block-like M-A particles were mostly along prior austenite grain boundaries and polygonal ferrite boundaries. The M-A constituent in a stringer form was along the bainite lath boundaries, while the connected or near connected M-A particles were observed also along austenite grain boundaries and bainite lath boundaries.

Quantitative measurements were made from the SEM micrographs. The results of the quantification of the M-A phase in the simulated IC GC HAZ for the steels are given in Table 4. The size distribution data is compared in the histograms in Fig. 7. The difference between the average M-A particle size of the steels was quite small. However, the maximum M-A particle size was the largest in Steel $\mathrm{Nb}$ $9.3 \mu \mathrm{m}, 16.3 \mu \mathrm{m}$ and the smallest in Steel LV $5.6 \mu \mathrm{m}$, 

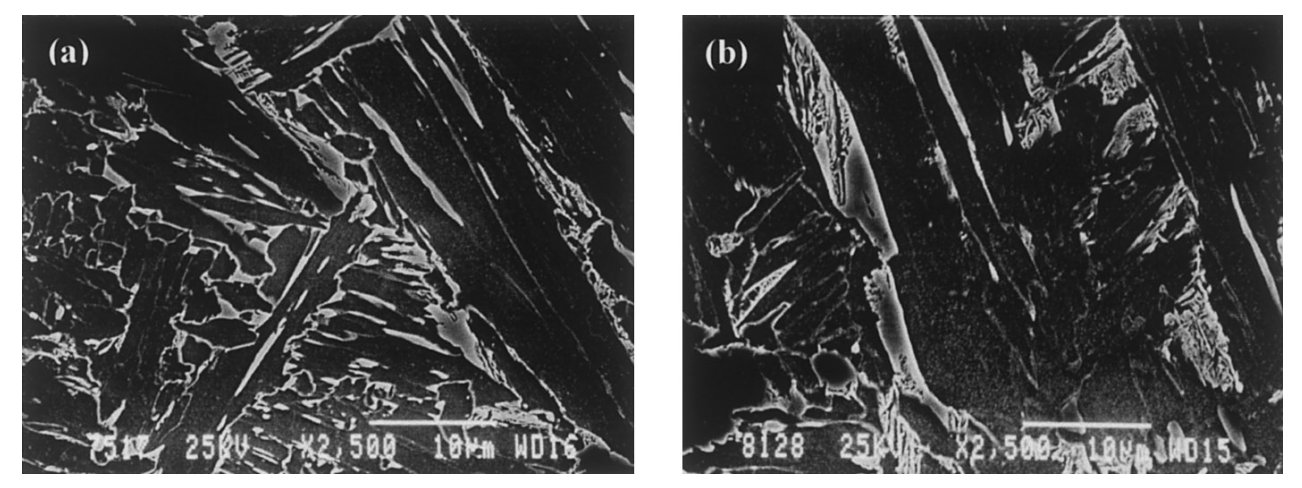

Fig. 6.

SEM micrographs showing the blocklike M-A particles on the prior austenite grain boundary and the polygonal ferrite grain boundaries, and stringer M-A particles along lath boundaries. They also show (a) the near connected M-A particles on the prior austenite grain boundary and (b) on the lath boundary.

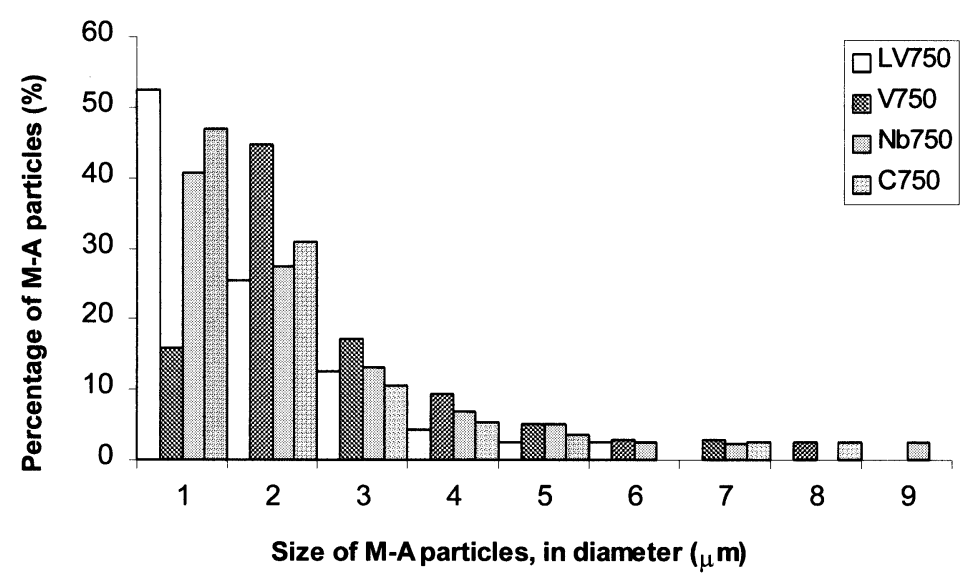

(a)

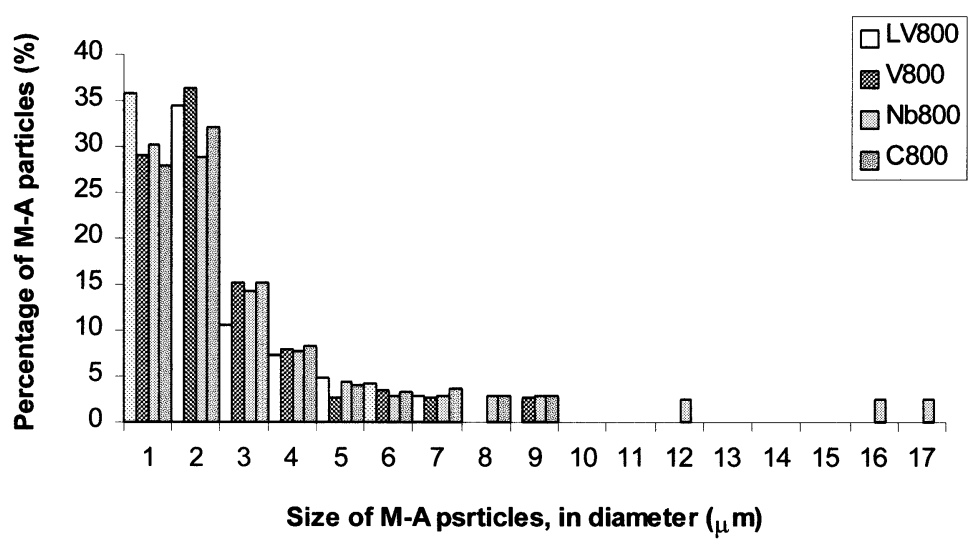

(b)

Fig. 7. Size distributions of M-A particles in the simulated (a) $750^{\circ} \mathrm{C} \mathrm{IC} \mathrm{GC} \mathrm{and} \mathrm{(b)} 800^{\circ} \mathrm{C}$ IC GC HAZ.

Table 4. Size and area fraction of the M-A particles in the simulated IC GC HAZ

\begin{tabular}{|c|c|c|c|}
\hline Code & $\begin{array}{c}\text { Average Size of M-A } \\
\text { in Diameter }(\mu \mathrm{m})\end{array}$ & $\begin{array}{c}\text { Maximum Size of M-A } \\
\text { in Diameter }(\mu \mathrm{m})\end{array}$ & $\begin{array}{c}\text { Area of M-A } \\
(\%)\end{array}$ \\
\hline Steel C750 & 1.3 & 7.3 & $4.1 \pm 1.6$ \\
\hline Steel VL750 & 1.6 & 5.6 & $3.0 \pm 0.9$ \\
\hline Steel V750 & 1.9 & 8.3 & $5.6 \pm 1.3$ \\
\hline Steel Nb750 & 1.9 & 9.3 & $4.7 \pm 1.5$ \\
\hline Steel C800 & 1.8 & 8.2 & $5.8 \pm 1.6$ \\
\hline Steel VL800 & 2.0 & 7.0 & $4.0 \pm 1.4$ \\
\hline Steel V800 & 1.6 & 8.5 & $4.5 \pm 1.0$ \\
\hline Steel Nb800 & 2.3 & 16.3 & $6.3 \pm 1.4$ \\
\hline
\end{tabular}

$7.0 \mu \mathrm{m}$ after both $750^{\circ} \mathrm{C}$ and $800^{\circ} \mathrm{C}$ reheating. Increasing the vanadium addition from $0.05 \%$ to $0.11 \%$ increased the maximum M-A particles size from $5.6 \mu \mathrm{m}$ to $8.3 \mu \mathrm{m}$ for $750^{\circ} \mathrm{C}$ cycle and from 7.0 to $8.5 \mu \mathrm{m}$ for $800^{\circ} \mathrm{C}$ cycle.

The amount of M-A islands showed a minimum in Steel LV after the intercritical cycles. The highest percentage of M-A phase was in the Steel V after $750^{\circ} \mathrm{C}$ cycle $(5.6 \%)$ and in Steel $\mathrm{Nb}$ after $800^{\circ} \mathrm{C}$ cycle $(6.3 \%)$. There was a bigger scatter in the area fraction values, because the distribution of the M-A constituent in the IC GC HAZ was not uniform.

250 fields were analysed on the SEM display screen for each specimen at a magnification of 2500 times and the results are given in Table 5. After the $750^{\circ} \mathrm{C}$ cycle, the number fields with M-A phase was higher in Steel V (97\%) than in the other steels (79-84\%). There were fewer fields with stringer M-A in Steel LV (16\%) than in the other 
steels $(25-26 \%)$. However, the percentages of the prior austenite grain boundaries with M-A particles or with connected or near-connected M-A particles were the highest in Steel $\mathrm{Nb}$ and the lowest in Steel LV. After the $800^{\circ} \mathrm{C}$ cycle, $100 \%$ of the fields with M-A phase were observed in Steel $\mathrm{Nb}$ and about $90 \%$ of the fields with $\mathrm{M}-\mathrm{A}$ phase was found in the other steels. The number of fields with stringer M-A phase was higher in Steel $\mathrm{Nb}$ and Steel $\mathrm{C}$ than in the vanadium steels. Again, the percentages of the grain boundaries with M-A particles, or with connected or near-connected

Table 5. Distribution of M-A phase in the IC GC HAZ.

\begin{tabular}{|c|c|c|c|c|c|c|c|c|}
\hline \multirow{3}{*}{ Code } & \multicolumn{4}{|c|}{$750^{\circ} \mathrm{C}$ IC GC HAZ } & \multicolumn{4}{|c|}{$800^{\circ} \mathrm{C}$ IC GC HAZ } \\
\hline & \multicolumn{2}{|c|}{$\begin{array}{c}\% \text { field with } \\
\text { M-A }\end{array}$} & \multicolumn{2}{|c|}{$\begin{array}{c}\% \text { prior austenite } \\
\text { grain boundaries } \\
\text { with M-A }\end{array}$} & \multicolumn{2}{|c|}{$\begin{array}{l}\% \text { field with } \\
\text { M-A }\end{array}$} & \multicolumn{2}{|c|}{$\begin{array}{c}\% \text { prior austenite } \\
\text { grain boundaries } \\
\text { with } \mathrm{M}-\mathrm{A}\end{array}$} \\
\hline & M-A & $\begin{array}{l}\text { Stringer } \\
\text { M-A }\end{array}$ & M-A & $\begin{array}{c}\text { Connected } \\
\text { M-A }\end{array}$ & M-A & $\begin{array}{c}\text { Stringer } \\
\text { M-A }\end{array}$ & M-A & $\begin{array}{c}\text { Connected } \\
\text { M-A }\end{array}$ \\
\hline Steel C & 80 & 26 & 72 & 13 & 89 & 38 & 80 & 20 \\
\hline & 79 & $T$ & 49 & 4 & 92 & 15 & 69 & 12 \\
\hline Steel V & 97 & 25 & 76 & 16 & 94 & 13 & 88 & 25 \\
\hline Steel Nb & 84 & 25 & 77 & 19 & 100 & 40 & 100 & 42 \\
\hline
\end{tabular}

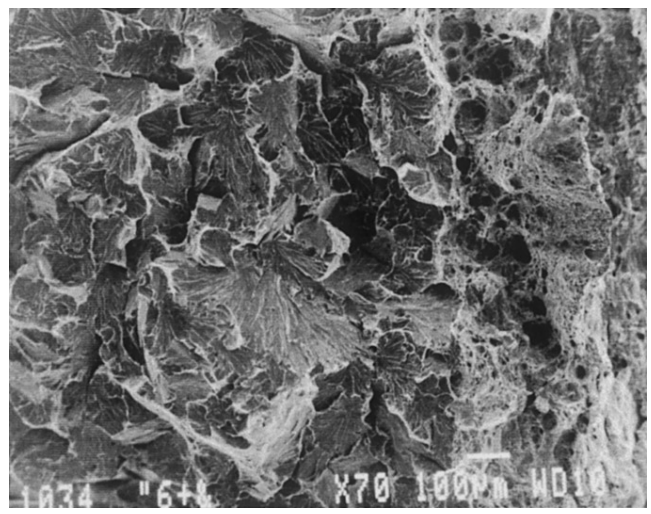

Fig. 9. SEM fractograph showing a narrow dimple region at the initiation site and a cleavage fracture region.
M-A particles, were the highest in Steel $\mathrm{Nb}$ and the lowest in Steel LV.

$\mathrm{Fe}_{3} \mathrm{C}$ particles of thickness $<0.5 \mu \mathrm{m}$ were observed on the bainitic lath boundaries and on polygonal ferrite boundaries. The carbides were frequently found as stringers in Steel C, but more broken up in the vanadium steels (Fig. 8). Only a few carbides were observed in Steel $\mathrm{Nb}$.

\subsection{Fractographic Evaluation of the Broken Charpy} and CTOD Specimens and Microstructural Examination on the Sections Perpendicular to Fracture Surface

Fracture surfaces of the IC CG HAZ Charpy and CTOD specimens were examined using the SEM to determine the fracture morphology. Figure 9 is a fractograph showing an example of the fracture surface, which was observed in the Charpy and CTOD specimens. At the initiation site, a narrow dimpled region, with varying width, was observed on the fracture surface. A transition in the fracture mode from ductile to cleavage was evident during crack advancement. The fracture mode in the propagation region was primarily cleavage, associated with a small extent of ductile tearing (about 10\%). All the steels exhibited irregular facets in the cleavage regime. The fracture mode of all the steels was identical and it was a function of the test temperature, in terms of a transition from dimple-to-cleavage, with a decrease in the temperature.

On the etched fracture surface of the Charpy impact and the CTOD specimens, larger M-A particles were found at or close to the initiation point. An example of the clear initiation site on the fracture surface of the Charpy impact specimen is shown in Fig. 10(a). Closer examination of this area revealed that the initiation occurred from the cracked blocky particles, lying on a prior austenite grain boundary (Fig. 10(b)). The blocky features correspond in size and
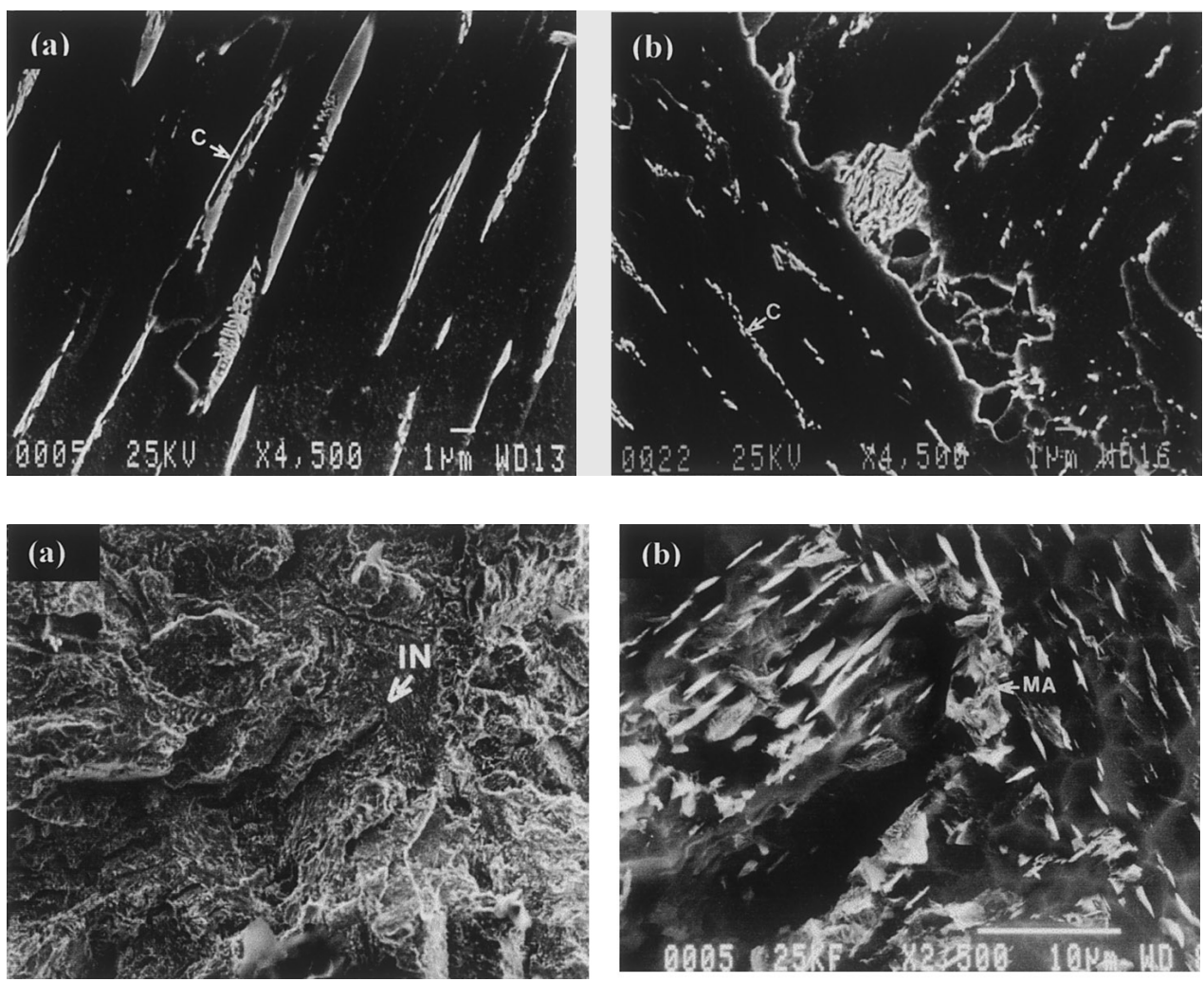

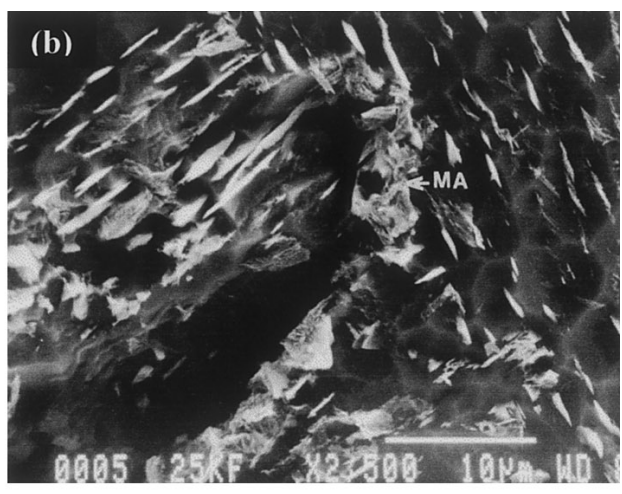

Fig. 8.

SEM micrographs showing (a) the stringer carbides on the lath boundaries in Steel C and (b) broken carbides on the lath boundaries and polygonal ferrite boundaries in Steel $\mathrm{V}$.

Fig. 10.

SEM fractographs showing (a) the initiation site on the fracture surface of the Charpy impact specimen and (b) the initiation from the blocky MA particles at a prior austenite grain boundary and the crack path following the prior austenite grain boundary. 

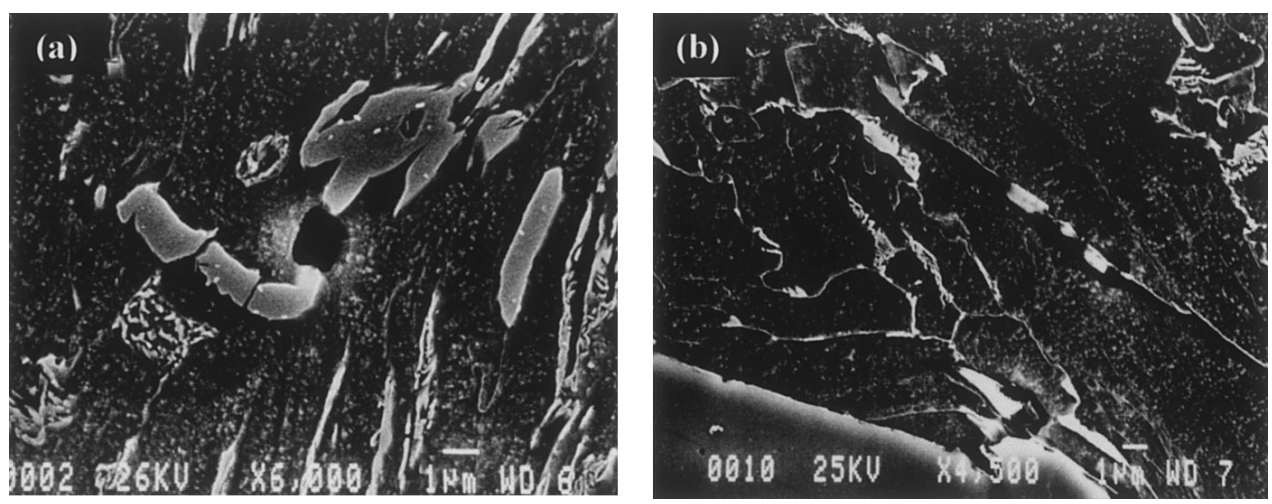

Fig. 11.

SEM micrographs showing (a) particle cracking and a void between two closely spaced M-A particles and (b) debonding at ferrite/stringer M-A interface and cracking of the stringer M-A particle.

shape to the block M-A particles seen in the IC GC HAZ microstructure. The EDX analysis showed that there was no detectable compositional variation between the blocky features and the matrix on the fracture surface and indicated that the blocky features were not inclusions. In accordance with other published work, ${ }^{2,3)}$ these observations suggest that the blocky features are the M-A constituent.

Debonding of M-A particles from the surrounding matrix was found in all the Charpy impact and the CTOD specimens examined. Examples are given in Fig. 11. Figure 11(a) shows the debonding between two closely spaced MA regions. A cracked stringer M-A particle, debonded from the ferrite matrix, can be seen in Fig. 11(b).

\section{Discussion}

The steel with the $0.05 \% \mathrm{~V}$ addition had the best IC CG HAZ toughness compared with the other steels, but increasing the vanadium addition to $0.11 \%$, decreased the IC CG HAZ toughness. The beneficial effect of vanadium on the matrix microstructure, i.e. the promotion of more acicular ferrite and grain boundary polygonal ferrite, was observed in both Steel LV and Steel V. However, the size and density of the M-A phase in the IC CG HAZ were different in the two steels. Steel LV showed the smaller size of M-A particles and the lower area fraction of M-A phase compared with the other steel. The addition of $0.031 \mathrm{wt} \% \mathrm{Nb}$ produced both the largest size of M-A particles and the greatest area fraction of M-A phase, and reduced the IC CG HAZ toughness.

\subsection{Effect of M-A Phase on the IC GC HAZ}

Area fraction of M-A phase is an important factor for the IC GC HAZ toughness. It has been reported ${ }^{5,20)}$ that the drastic decrease in the Charpy and CTOD values at the IC GC HAZ can be attributed mainly to the increase in the amount of M-A phase, regardless of the thermal cycles and the steel types. Matsuda et $a l^{21)}$ observed that both the initiation energy and the propagation energy markedly decreased as the area fraction of M-A phase increased. In the present work, a relation between the area fraction and Charpy impact transition temperature was found (Fig. 12(a)). Steel LV had the smallest area fraction of M-A phase, which correlated with the lowest Charpy impact transition temperature, while Steel $\mathrm{Nb}$, after $800^{\circ} \mathrm{C}$ reheating, with the largest area fraction of M-A phase, had the highest Charpy impact transition temperature. Increasing the vanadium addition to $0.11 \%$ increased the area fraction

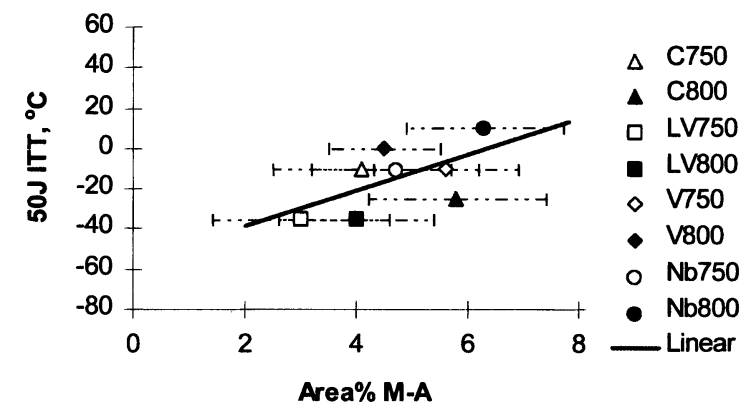

(a)

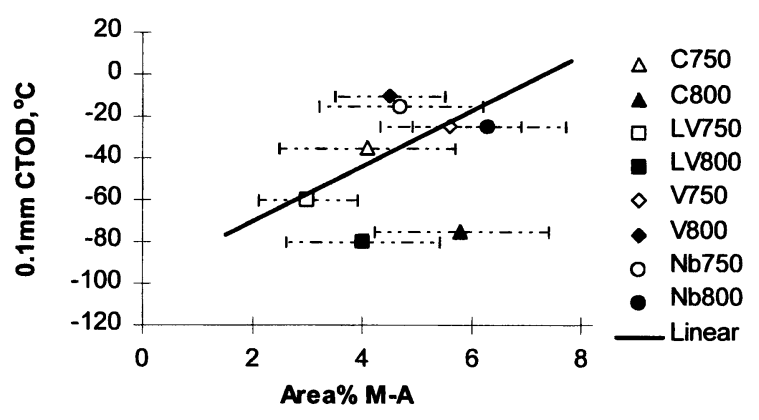

(b)

Fig. 12. The effects of area fraction of M-A phase on (a) the 50J Charpy impact transition temperature and (b) CTOD transition temperature of the IC GC HAZ.

of M-A phase and decreased the toughness of the IC GC HAZ. However, the data as a function of the CTOD toughness of the IC GC HAZ (Fig. 12(b)) showed a greater scatter than the data for Charpy 50J ITT.

Another main parameter, which is identified in this work as an important influence on the HAZ toughness, is the size of M-A particles, especially the maximum size. It has been reported that the larger $\mathrm{M}-\mathrm{A}$ islands are significant in reducing HAZ toughness. ${ }^{3,7,22,23)}$ Tagawa et al. ${ }^{23)}$ found that for a relative low volume fraction (5\%) of the M-A islands, the cleavage fracture stress seemed to be dependent on the maximum size of the martensite. The work by Montermarano ${ }^{24)}$ indicated that in the case of steel with large M-A particles, microcrack nucleation occurs at the interface between the large M-A particles and the ferrite matrix. In the work of Davis and King ${ }^{3,7)}$ on a steel of composition C 0.082, Mn 1.23, Ti 0.011, V 0.05 and N 0.007, which was intercritically reheated under similar conditions 


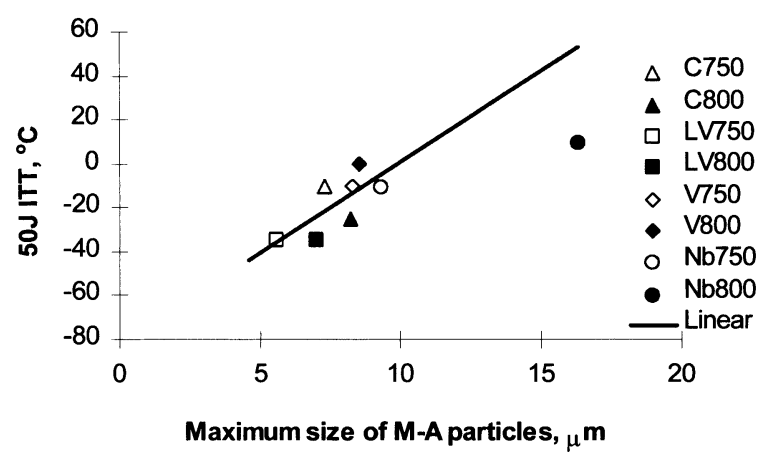

(a)

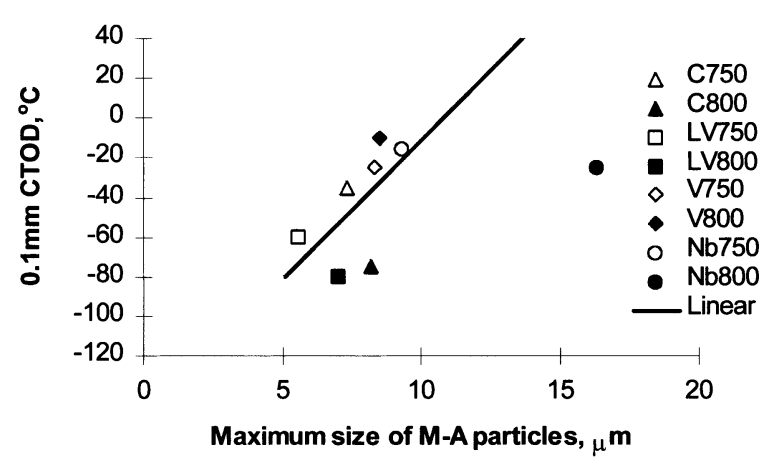

(b)

Fig. 13. The effect of maximum M-A particles size on (a) the 50J ITT and (b) $0.1 \mathrm{~mm}$ CTOD TT.

to those used in the present work, it was concluded that the minimum impact toughness value for IC GC HAZ structures is not simply associated with the maximum amount of M-A constituent. It requires a particular microstructure: one with a nearly connected grain boundary network of blocky M-A particles, which are significantly harder than the internal grain microstructure, and the absence of grain refinement within the large prior austenite grains.

The influence of the large M-A particle on the HAZ toughness is confirmed by the present work. The effects of the maximum size of M-A particles on (a) the Charpy impact transition temperature or (b) the $0.1 \mathrm{~mm}$ CTOD transition temperature, can be seen in Fig. 13. A best-fit line has been drawn for the data in Figs. 13(a) and 13(b) for the seven points, which are bunched. The justification for omitting the data from $\mathrm{Nb800}$ is that a considerable number of connected M-A particles were observed in this specimen, which give a significantly larger size than for the other seven specimens. A trend of an increase in the Charpy ITT or CTOD TT with an increase in the maximum size of M-A phase can be seen. Steel LV had the smallest maximum size of M-A phase and the best IC GC HAZ toughness, followed by the Steel $\mathrm{C}$, then Steel $\mathrm{V}$ and finally Steel $\mathrm{Nb}$. Again, the $\mathrm{Nb}$ steel showed the largest maximum size of $\mathrm{M}$ A phase, which correlated with the highest Charpy ITT and CTOD TT.

From Figs. 12 and 13, it can be seen that the Charpy ITT had a better fit with the amount and size of M-A particles than the CTOD data, since the notch root radius of CTOD test specimens was smaller than that of Charpy impact test

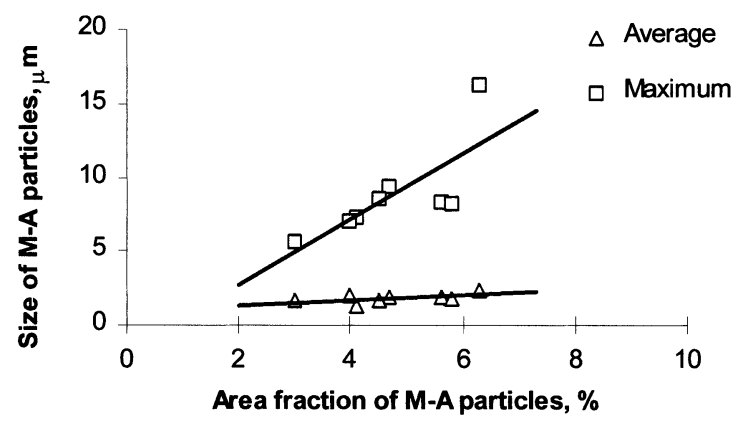

Fig 14. The relation between the area fraction and the size of MA particles.

specimens. The high-stress and high-strain region at the root for CTOD test specimens was smaller as well, thereby increasing the susceptibility to the influence of the local brittle phase in the HAZ. The notch position in the IC CG $\mathrm{HAZ}$ is a very important factor in influencing the CTOD result and it can cause a wide scatter within the test data.

The relation between the area fraction of the M-A phase and the size of M-A particles is given in Fig. 14. This shows that the maximum size of M-A particles increases with an increase of the area fraction of M-A phase, while the average size of M-A particles seems almost constant. Mintz, ${ }^{25,26)}$ who studied ferrite-pearlite steels following the work of McMahon and Cohen ${ }^{27)}$ concluded that in the case of grain boundaries, the thickness of the carbide films has the most important influence on the Charpy impact transition temperature; carbide density has also been shown to have a smaller but detrimental influence. Increasing the number of carbides at the grain boundaries increases the statistical probability of carbide cracking and the crack propagation through the ferrite. It could also be imagined that if the carbide cracks and the crack propagates to the other side of the grain, its propagation into the next grain will be easier if there is another brittle particle sited at this grain boundary, directly in front of the crack path. ${ }^{28)} \mathrm{A}$ similar behaviour would be expected from the brittle and hard M-A phase, as the coverage of the boundaries increases. However, the size of the M-A phase is than an order of magnitude greater than the thickness of cementite observed in the present study.

By noting the number of fields containing M-A particles of size $>0.5 \mu \mathrm{m}$, a more accurate picture of the distribution of M-A phase has been found. In the niobium steel, most of the fields $\left(100 \%\right.$ after the $800^{\circ} \mathrm{C}$ cycle and $84 \%$ after the $750^{\circ} \mathrm{C}$ cycle) contained M-A particles. The percentage of fields containing M-A phase was also found to be higher in the $0.11 \% \mathrm{~V}$ steel than in the $0.05 \% \mathrm{~V}$ steel. This observation coincides with the results of the area fraction of M-A phase in the steels. For the M-A phase distribution on the prior austenite grain boundaries, the percentages of the boundaries with M-A particles and with connected or nearly connected M-A particles were the highest in the niobium steel and the lowest in the $0.05 \% \mathrm{~V}$ steel. These results strongly support the theory presented by the previous research, ${ }^{3,19,29)}$ that the connected or nearly connected M-A particles on the prior austenite boundary control the HAZ toughness. 


\subsection{The Effect of Matrix Microstructure on the HAZ Toughness}

Matrix microstructures are also reported to have a strong influence on HAZ toughness. ${ }^{14,30-32)}$ In bainitic and martensitic steels, the austenite grains transform to lath structures. The lath structures occur in bundles or packets with low angle boundaries between the laths. A larger misorientation occurs across packet boundaries. In such structures, the packet width is the main microstructural feature controlling cleavage crack propagation. ${ }^{33-35)}$ It was reported ${ }^{34,35)}$ that the ductile-brittle transition temperature is a logarithmic function of the inverse square root of the product of the packet diameter. A linear increase in the HAZ CTOD transition temperature with the inverse square root of the cleavage facet size for a constant volume fracture of the M-A phase was also found in the works of Nakanishi et al. ${ }^{30)}$ and Haze and Aihara. ${ }^{31)}$

In the present work, the beneficial effect of a small addition of $0.05 \%$ vanadium on the matrix microstructure of the HAZ was affirmed. The intragranular microstructure of the vanadium steels was much finer, with an increased proportion of acicular ferrite, a reduced bainite colony size and very few coarse ferrite side-plates, which were common in the carbon manganese steel. The niobium steel had a higher proportion of ferrite side-plates. This tendency for a finer grained transformed microstructure in the vanadium steels is believed to be beneficial for cleavage resistance and to be the principal factor contributing to the observed CG HAZ toughness behaviour.

However, for IC GC HAZ, in the presence of large M-A islands, the effect of the microstructure on the HAZ toughness is rather more complicated. The improvement in the IC CG HAZ toughness in Steel LV may be brought about by the beneficial effects of vanadium on the matrix microstructure and a reduction in both size and area fraction of M-A phase. But in Steel V, the beneficial effect of vanadium on the matrix microstructure is overcome by the detrimental effect of the increased area fraction and size of M-A particles. It is suggested that when large M-A particles are present, the packet size is not the single dominant factor in influencing the fracture mechanism in the IC CG HAZ.

\subsection{The Relation between the Hardness and Toughness in the IC GC HAZ}

The hardness in the GC HAZ was similar for the vanadium and niobium steels (202-208 HV), but lower in Steel C (187 HV). Following the intercritical reheating, Steel C and Steel LV underwent a significant hardness reduction, whereas the hardness of Steel V and Steel Nb was virtually unchanged. The reduction in hardness in Steel C and Steel $\mathrm{LV}$ was probably associated with the recovery processes in these two steels. The insensitivity of the hardness of Steel $\mathrm{V}$ and Steel $\mathrm{Nb}$ to the intercritical thermal cycle may be due to retardation of recovery processes by vanadium and niobium precipitates, or possibly by further vanadium and niobium precipitation.

The effect of hardness on the $0.1 \mathrm{~mm}$ CTOD transition temperature is demonstrated in Fig. 15. It can be seen that Steel $\mathrm{V}$ and Steel $\mathrm{Nb}$ had the higher hardness and also the higher $0.1 \mathrm{~mm}$ CTOD TT. However, Steel LV showed no deterioration in the IC GC HAZ toughness in comparison

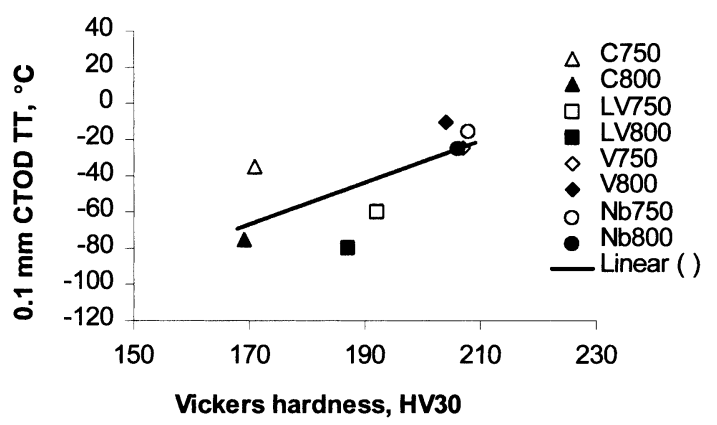

Fig. 15. The effect of hardness on the $0.1 \mathrm{~mm}$ CTOD TT in the IC GC HAZ.

with Steel C, despite having a higher hardness. This shows that the toughness results cannot be explained by changes in hardness alone, and that the other microstructural factors, such as the area fraction and distribution of M-A, and the benefit of vanadium on microstructure, must also be incorporated.

\subsection{The Effects of Vanadium and Niobium on Formation of M-A Phase in the IC GC HAZ}

From the microstructural analysis, the drastic drop in the IC GC HAZ toughness with addition of $0.031 \% \mathrm{Nb}$ is mainly attributed hardening by martensite, since niobium increases the hardenability of austenite. It was suggested ${ }^{6}$ that the addition of niobium to low carbon steels has a pronounced effect in lowering the $\mathrm{A}_{\mathrm{r} 3}$ transformation temperature. A small addition of niobium $(\sim 0.02 \mathrm{wt} \%)$ is known to suppress ferrite nucleation at the prior austenite grain boundaries and increase the volume fraction of martensite or bainite. ${ }^{11)}$ Amin and Pickering ${ }^{36)}$ proposed a possible mechanism whereby dissolved niobium could reduce the ferrite nucleation and growth rate during cooling. Their argument was specifically concerned with possible effects of lowering the $\mathrm{A}_{\mathrm{r} 3}$ temperature, which would be a key parameter to the intercritical temperature region. When the transformation temperature is lowered, the ferrite transformation, through a diffusional process, is inhibited, and a bainitic or martensitic structure is easily formed.

The effect of vanadium on the IC CG HAZ is not fully understood. It was regarded by some, ${ }^{14,15)}$ that vanadium has a detrimental effect on toughness of the IC GC HAZ, because vanadium can promote the formation of M-A phase. However, the tendency for M-A formation will depend on the overall alloy content and cooling rate. ${ }^{8}$ A detailed examination of these publications does show that the steels containing at least $0.0025 \%$ boron which could mask an effect of vanadium. On the other hand, a beneficial effect of vanadium on the IC CG HAZ toughness has also been also found. ${ }^{16-18)}$ Crowther ${ }^{18)}$ suggested that during the intercritical thermal cycle, re-austenitisation occurs preferentially between Widmanstatten ferrite and bainitic ferrite plates, and also at austenite grain boundaries, leading to the formation of M-A phase in these areas. The more complete outlinement of the austenite grains by pearlite and M-A particles may be related to the lack of polygonal ferrite at the austenite grain boundary. According to this view, the nucleation sites for re-austenitsation will be fewer in vanadium steels than other steels, and the area fraction of M-A phase in the IC CG HAZ will be reduced. This may explain the 
improvement of IC CG HAZ toughness in the $0.05 \% \mathrm{~V}$ steel. However, both the area fraction and size of M-A were increased in the $0.11 \% \mathrm{~V}$ steel. It is therefore suggested that the effect of vanadium on the hardenability of austenite in the IC CG HAZ was different in the two steels.

It has been reported that vanadium can exert either a beneficial or detrimental effect on hardenability, depending on the level of vanadium content and the solution treatment temperature. ${ }^{37,38)}$ It was argued that when vanadium is in solid solution in austenite, it has a strong effect on hardenability. It was postulated by Pickering ${ }^{39)}$ that the strong effect of vanadium on hardenability is due to vanadium atoms, possibly in association with $\mathrm{C}$ and $\mathrm{N}$ atoms, segregating to the austenite grain boundaries at low austenite temperatures, with a consequent inhibition of grain boundary nucleation of non-martensite transformation products and an increase in hardenability. In the present study, Steel LV and Steel V had similar GC HAZ hardness, suggesting that the state of $\mathrm{V}(\mathrm{C}, \mathrm{N})$ precipitation was similar in both of the steels after the first thermal cycle. Therefore, during the second thermal cycle there should be more vanadium in solution before $\gamma-\alpha$ transition in Steel V than in Steel LV. An addition of $0.05 \% \mathrm{~V}$ to the boron free $\mathrm{C}-\mathrm{Mn}$ steel did not have a significant effect on the hardenability of the austenite. On the contrary, Steel LV had the lowest area fraction and the smallest size of M-A phase and a superior IC GC HAZ toughness to the other steels. However, increasing the vanadium content from $0.05 \%$ to $0.11 \%$ may increase the effect of vanadium on the hardenability of austenite and lead to the observed increase of area fraction and size of MA phase in Steel V.

\section{Conclusions}

(1) In the present study on the simulation of the intercritical reheated coarse grained heat affected zone of microalloyed steels, the addition of $0.05 \% \mathrm{~V}$ to the $\mathrm{C}-\mathrm{Mn}$ steel resulted in the lowest IC CG HAZ CTOD and Charpy transition temperatures. The area fraction of the M-A phase and size of the M-A particles supported this data. Raising the level of vanadium to $0.11 \%$ resulted in a greater area fraction of the M-A phase, larger average and maximum sizes of M-A particles, significantly more fields containing $\mathrm{M}-\mathrm{A}$ phase and a deterioration in toughness.

(2) The addition of $0.031 \% \mathrm{Nb}$ produced the largest size of M-A phase and the greatest area fraction for the group of steels tested in this study. With the exception of the CTOD data for the $0.11 \% \mathrm{~V}$ steel reheated at $800^{\circ} \mathrm{C}$, the $\mathrm{Nb}$ steel gave the poorest toughness data of the series.

(3) The presence of the M-A phase is the dominant factor in determining the toughness of IC CG HAZ. In addition, this study has identified correlations between the IC GC HAZ toughness and area fraction of M-A phase and maximum size of M-A particles.

\section{Acknowledgements}

The authors wish to thank Dr. W. B. Morrison, Corus Group, Swinden Technology Centre, for his advice throughout the project. One of the authors (YLI) would like to thank the University of Strathclyde, British Steel plc., Swinden Technology Centre and Vanadium International
Technology Committee (Vanitec) for providing a scholarship and financial support during this study.

\section{REFERENCES}

1) K. Easterling: Introduction to the Physical Metallurgy of Welding, Butterworth-Heinemann, Oxford, (1992).

2) B. C. Kim, S. Lee, N. Kim and D. Y. Lee: Metall. Trans. A, 22A (1991), 139.

3) C. L. Davis and J. E. King: Mater. Sci. Technol., 9 (1993), 8.

4) C. L. Davis: PhD thesis, University of Cambridge, (1994).

5) O. M. Akselsen, O. Grong and J. K. Solberg: Mater. Sci. Technol., 3 (1987), 649.

6) S. Lee, B. Chun and D. Kwon: Metall. Trans. A, 23A (1992), 2803.

7) C. L. Davis and J. E. King: Metall. Trans. A, 25A (1994), 563.

8) A. Barnes: Welding Institute Bulletin, Sept/Oct. (1990), 94.

9) G. R. Wang, T. H. North and K. G. Lewis: Weld. J., 69 (1990), 14.

10) K. Abe, M. Shimizu, S. Takashima and H. Kaji: Int. Conf. on Physical Metallurgy of Thermomechanical Processing of Steels and Other Metals, ed by I. Tamura, ISIJ, Tokyo, (1988), 322.

11) S. Okaguchi, T. Hashimoto and H. Ohtani: Int. Conf. on Physical Metallurgy of Thermomechanical Processing of Steels and Other Metals, ed. by I. Tamura, ISIJ, Tokyo, (1988), 330.

12) P. H. M. Hart and P. S. Mitchell: Weld. J., 74 (1995), 239.

13) D. N. Crowther: Report No. SL/PP/RSC/S12005/1/95/X, British Steel plc., Swinden Laboratories, (1995).

14) K. Uchino and Y. Ohno: Proc. 6th Int. Offshore Mechanics and Arctic Engineering Symposium, Houston, Texas, March (1987), 159.

15) P. L. Harrison and S. E. Webster: 36th MWSP Conf. Proc. ISSAIME, Warrendale, PA. XXXII, (1995), 551.

16) P. S. Mitchell, P. H. M. Hart and W. B. Morrison: Proc. Microalloying 95', ISS, Warrendale, PA, (1995), 149.

17) Y. Li, D. N. Crowther, M. J. W. Green, P. S. Mitchell and T. N. Baker: Thermomechanical Processing of Steels, The Institute of Materials, London, (2000), 69.

18) D. N. Crowther: Report No. SL/PP/RSC/S11826/2/94/X, British Steel plc., Swinden Laboratories, (1994).

19) O. M. Akselsen, J. K. Solberg and O. Grong: Scand. J. Metall., 17 (1988), 194.

20) A. Aihara and K. Okeuchi: Weld. Res. Counc. Bull., 373 (1992), 33.

21) F. Matsuda, K. Ikeuchi, Y. Fukada, Y. Horii, H. Okada, T. Shiwafu, C. Shoga and S. Suzuki: Weld. World, 38 (1996), 36.

22) I. Hrivnak, F. Matauda and K. Ikeuchi: Transactions of JERI, 21 (1992), 101.

23) T. Tagawa, T. Miyata, S. Aihara and K. Okamoto: Int. Symp. on Low Carbon Steels for the 90's, The Minerals, Metals and Materials Society, Warrendale, PA, (1993), 493.

24) T. W. Montemarano: Journal of Ship Production, 2 (1986), 145.

25) B. Mintz: Advances in Fracture Research, Vol. 2, Pergamon Press, Oxford, (1984), 1247.

26) B. Mintz and J. Kolahi-aval: Mater. Sci. Technol., 2 (1986), 1046.

27) C. J. McMahon and M. Cohen: Acta Metall., 13 (1965), 591.

28) B. Mintz: Metall. Trans. A, 28A (1997), 2073.

29) K. Ikeuchi, J. Liao, H. Tanabe and F. Matsuda: ISIJ. Int., 35 (1995), 1203.

30) M. Nakanishi, Y. Komizo and Y. Fukada: Q. J. Jpn. Weld. Soc., 4 (1986), 447.

31) T. Haze and S. Aihara: Offshore Machanical and Arctic Engineering, ASME, 3 (1988), 515.

32) B. de. Meester: ISIJ Int., 37 (1997), 537.

33) M. J. Roberts: Metall. Trans. A, 1 (1970), 3287.

34) J. P. Naylor and P. R. Krahe: Metall. Trans. A, 5A (1974) 1699

35) T. N. Baker and R. L. Reuben: Advances in the Physical Metallurgy and Application of Steels, The Metals Society, Liverpool, (1981), 213.

36) P. K. Amin and F. B. Pickering: Thermomechanical Processing of Microalloyed Austenite, ed by A. J. DeArdo et al., AIME, Warrendale, PA, (1983), 337.

37) F. B. Pickering: HSLA Steel: Metallurgy and Applications, ASM International, Metals Park, OH, (1995), 305.

38) D. T. Llewellyn: Ironmaking Steelmaking, 23 (1996), 397.

39) F. B. Pickering: HSLA Steel: Technology and Application, ASM, Metals Park, OH, (1984), 1. 